\title{
Exhaled and arterial levels of endothelin-I are increased and correlate with pulmonary systolic pressure in COPD with pulmonary hypertension
}

\author{
Pierluigi Carratu*1, Cristina Scoditti ${ }^{1}$, Mauro Maniscalco ${ }^{2}$, \\ Teresa Maria Seccia1, Giuseppe Di Gioia1, Felice Gadaleta1, \\ Rosa Angela Cardone ${ }^{3}$, Silvano Dragonieri ${ }^{1}$, Paola Pierucci ${ }^{1}$, \\ Antonio Spanevello ${ }^{4}$ and Onofrio Resta ${ }^{1}$
}

Address: ${ }^{1}$ Institute of Pulmonary Disease, University of Bari, Italy, ${ }^{2}$ Institute of Pulmonary Disease, University of Naples, Italy, ${ }^{3}$ Department of General and Environmental Physiology, University of Bari, Italy and ${ }^{4}$ Institute of Pulmonary Disease, University of Foggia, Italy

Email: Pierluigi Carratu* - pierluigicarratu@yahoo.com; Cristina Scoditti - c_scod@yahoo.it;

Mauro Maniscalco - mauromaniscalco@hotmail.com; Teresa Maria Seccia - tmseccia@uniba.it; Giuseppe Di Gioia - digioia@tin.it;

Felice Gadaleta - fgada@yahoo.it; Rosa Angela Cardone - rcarda@libero.it; Silvano Dragonieri - sidra@uniba.it; Paola Pierucci - papi@libero.it; Antonio Spanevello - aspa@tin.it; Onofrio Resta - oresta@pneumol.uniba.it

* Corresponding author

Published: 26 September 2008

BMC Pulmonary Medicine 2008, 8:20 doi:I0.1 I86/I47I-2466-8-20
Received: 12 March 2008

Accepted: 26 September 2008

This article is available from: http://www.biomedcentral.com/147I-2466/8/20

(C) 2008 Carratu et al; licensee BioMed Central Ltd.

This is an Open Access article distributed under the terms of the Creative Commons Attribution License (http://creativecommons.org/licenses/by/2.0), which permits unrestricted use, distribution, and reproduction in any medium, provided the original work is properly cited.

\begin{abstract}
Background: Endothelin-I (ET-I) and Nitric Oxide (NO) are crucial mediators for establishing pulmonary artery hypertension (PAH). We tested the hypothesis that their imbalance might also occur in COPD patients with PAH.

Methods: The aims of the study were to measure exhaled breath condensate (EBC) and circulating levels of ET-I, as well as exhaled NO (FENO) levels by, respectively, a specific enzyme immunoassay kit, and by chemiluminescence analysis in 3 groups of subjects: COPD with PAH (I2), COPD only (36), and healthy individuals (15). In order to evaluate pulmonary-artery systolic pressure ( $\mathrm{PaPs})$, all COPD patients underwent Echo-Doppler assessment.

Results: Significantly increased exhaled and circulating levels of ET-I were found in COPD with PAH compared to both COPD $(\mathrm{p}<0.000 \mathrm{I})$ only, and healthy controls $(\mathrm{p}<0.000 \mathrm{I})$. In COPD with $\mathrm{PAH}$, linear regression analysis showed good correlation between ET-I in EBC and PaPs $(r=0.621$; $p=0.03 \mathrm{I})$, and between arterial levels of ET-I and PaPs $(r=0.648 ; p=0.022)$, while arterial levels of ET-I inversely correlated with FEV $\%,(r=-0.59, p=0.043)$, and PaPs negatively correlated to $\mathrm{PaO}_{2}(r=-0.618 ; p=0.032)$. Significantly reduced levels of FENO were found in COPD associated with PAH, compared to COPD only $(22.92 \pm 11.38$ vs.35.07 $\pm 17.53 \mathrm{ppb} ; \mathrm{p}=0.03)$. Thus, we observed an imbalanced output in the breath between ET-I and NO, as expression of pulmonary endothelium and epithelium impairment, in COPD with PAH compared to COPD only. Whether this imbalance is an early cause or result of PAH due to COPD is still unknown and deserves further investigations.
\end{abstract}




\section{Background}

Chronic obstructive pulmonary disease (COPD) is the fourth leading cause of morbidity and mortality in developed countries. Pulmonary artery hypertension (PAH), frequently observed in patients with advanced COPD, is considered a predictor of worse outcome $[1,2]$. PAH in COPD is mainly the result of hypoxic pulmonary vasoconstriction [3], however it has been recently shown also induced by pulmonary arterial walls remodelling, with aberrant intimal changes $[4,5]$. Further evidences suggest that the initial event in the natural history of pulmonary hypertension due to COPD is the lesion of pulmonary endothelium by cigarette-smoke products $[6,7]$, leading to critical changes in the expression of vascular mediators $[7,8]$, which are responsible for impairment of endothelial function. Among a wide spectrum of vasoactive mediators, endothelin-1 (ET-1) plays a pivotal role in exerting vasoconstriction [9], bronchoconstriction [10], vascular [11] and airway [12] cells proliferation, via $\mathrm{ET}_{\mathrm{A}}$ and $\mathrm{ET}_{\mathrm{B}}$ receptors $[13,14]$. Increased expression of ET-1, it has been identified in the vessels of patients with IPAH [15]. Plasma [16,17], induced sputum [18], and urinary [17] levels of ET-1 are augmented in patients with COPD; however, there are still contrasting data about circulating ET-1 levels in COPD patients with PAH [19-21]. In addition, no data are yet available on ET-1 levels in exhaled breath condensate of COPD patients.

Nitric oxide (NO), produced by endothelial cells, is the central stimulus for releasing and dilating pulmonary arterial vasculature [22]. NO production is oxygen dependent and lack of NO synthesis, under hypoxic conditions such as COPD, contributes to chronic hypoxic pulmonary vasoconstriction [23], leading to pulmonary artery hypertension [24]. It is now appreciated that NO release is impaired in the pulmonary vasculature of COPD patients [25], while exhaled NO levels, increased in COPD [26], are significantly reduced in COPD associated with PAH [27]. An imbalance between the excretion of vascular mediators has been shown important for developing idiopathic pulmonary hypertension [8] and might be also responsible in promoting secondary PAH [8]. We hypothesized a pathological dysregulation of exhaled output between ET-1 and NO in COPD with PAH. Despite several issues about reproducibility, variability and sensitivity, measurement of different biological markers in COPD is currently a useful assay in assessing disease pathogenesis, predicting progression, and monitoring adequate therapies [28]. The aims of the present study were to investigate exhaled breath condensate (EBC) and circulating levels of ET-1, as well as the exhaled NO (FENO) in COPD only, in COPD with pulmonary artery hypertension, and in a group of healthy subjects. We also examined whether concentrations of exhaled biomarkers, or circulating ET-1 levels were related to the severity of dis- ease, as defined by lung function, or pulmonary artery pressure.

\section{Methods}

The Institutional Review and the Ethical Boards of the University of Bari approved protocols and all patients signed informed consent before participating in this study.

\section{Patient population}

Sixty-three subjects were enrolled into the study at outpatient clinic of Institutes of pulmonary disease, University of Bari, from March 2004 to January 2007. Subjects were divided into three groups on the basis of pathological characteristics. The first group consisted of 12 patients with COPD (stage III and IV), diagnosed according to the American Thoracic Society (ATS) criteria [29] (11 males, mean age $70.8 \pm 6.7$ years), associated with PAH. All patients were ex smokers (mean pack-years, $26 \pm 7$ ) without a history of atopy and with normal IgE levels. Five patients had been receiving long-term domiciliary oxygen for at least 6 consecutive months.

A second group included 36 patients with COPD, diagnosed according to the American Thoracic Society (ATS) criteria (30). All patients (32 males, mean age 67.6 \pm 9.2 years) were ex smokers (mean pack-years, $25 \pm 6$ ) without a history of atopy and with normal IgE levels; six patients had been receiving long-term domiciliary oxygen for at least 6 consecutive months. 15 healthy non-smoking, non-atopic subjects ( 9 males, mean age $58 \pm 9.2$ years) were enrolled as controls. Patients with other organ failure, cancer, or inability to cooperate were excluded from the study. At the time of inclusion into the study, all the patients were in stable condition, and free from respiratory tract infection and/or acute exacerbation in the preceding 6 weeks. All of the patients were receiving their regular treatment with inhaled bronchodilators, but none was receiving systemic or inhaled steroids. No change in medical therapy was made in the week prior to the study.

\section{Pulmonary function test and arterial blood gas analysis}

Pulmonary function tests were performed in the pulmonary function laboratory of our Institutes at admission to the study. Static and dynamic lung volumes were measured by means of a constant-volume body plethysmograph (MasterScreen Body, Jaeger, Germany) and according to the guidelines of the American Thoracic Society (ATS) [30]. The best of three reproducible values was expressed as a percentage of the predicted normal value.

Arterial blood for the analysis of gases during room air breathing was drawn in all patients by radial artery in the supine position and after a 30 minute rest period. $\mathrm{PaO}_{2}$, 
$\mathrm{PaCO}_{2}$ and $\mathrm{pH}$ were measured in a blood gas analyzer (Model 1312; Instrumentation Laboratory; Milan, Italy).

\section{Echo-Doppler assessment}

All patients of groups 1-2-3 were investigated using realtime, phased array, two-dimensional Doppler (2-D) echocardiography (CFM 750 CV 2.5 or $3.25 \mathrm{MHz}$ transducer; GE Vingmed, Milan, Italy). The examinations were taken on patients in a semirecumbent left lateral position, and images were taken from subxiphoid, parasternal, and apical views. The mean value of three measurements was considered. Tricuspid valve regurgitation pressure was identified by color flow mapping, then, maximal pressure gradient between right ventricular and right atrial was obtained using the continuous wave Doppler on the guidance of the color Doppler signal of the tricuspid regurgitation. Peak pressure gradient measurement was estimated by means of a simplified Bernoulli equation [31]. Pulmonary-artery systolic pressure (PaPs) was calculated by adding the Bernoulli derived pressure gradient to an assumed right atrial pressure of $10 \mathrm{mmHg}$. A PaPs $\geq 35 \mathrm{mmHg}$ was considered as cut-off.

\section{Measurement of ET-I levels}

ET-1 was evaluated in the (EBC) as well as in arterial and venous blood of all the subjects. ET-1 was obtained by using a condenser non-invasively to collect the non-gaseous components of the expiratory air (EcoScreen: Jaeger, Würzburg, Germany). Subjects were instructed to breathe through a mouthpiece and a two-way, non-rebreathing valve, which also served as a saliva trap, in order to avoid contamination. They were asked to breathe at tidal volume, wearing a nose clip, for a period of $10 \mathrm{~min}$. The condensate (at least $1 \mathrm{ml}$ ) was transferred to centrifuges tubes and immediately stored at $-80^{\circ} \mathrm{C}$. Peripheral venous blood samples were obtained, in all subjects, from an antecubital vein after at least $30 \mathrm{~min}$ seated rest. Venous blood samples were collected in plastic tube containing ethylenediamine tetraacetic acid (EDTA), centrifuged at $5000 * \mathrm{~g}$ for $10 \mathrm{~min}$ and plasma was frozen and stored at $80^{\circ} \mathrm{C}$ until assay. Arterial blood gas analyses were performed in all subjects, while breathing room air, by radial artery in the supine position and after a 30 minute rest period. A specific enzyme immunoassay (EIA) kit (Cayman Chemical, Ann Arbor, Mich., USA) was used to measure ET- 1 concentrations in the breath condensate and in blood samples. The specificity of the test for ET-1 was $100 \%$, and the cut-off of the assay was considered a concentration $\geq 1.5 \mathrm{pg} / \mathrm{ml}$. The reproducibility of repeated ET-1 exhaled condensate measurements was assessed by the Bland and Altman method [32].

\section{NO measurement}

Exhaled NO was measured by a chemiluminescence analyzer (NOA Tm280; Sievers Instruments Inc., Boulder,
CO, USA) by the on-line single-breath technique, according to the ATS and ERS recommendations [33]. Subjects were asked to perform a single slow exhalation starting from total lung capacity through a mouthpiece against a resistance of $16 \mathrm{~cm} \mathrm{H}_{2} \mathrm{O}$ under a visual biofeedback, to maintain a $50 \mathrm{ml}$ second (s) steady flow. Subjects were at rest, sitting down, having refrained from eating and exercise for at least 2 hours, and breathed filtered NO-free air (air filter AFL 01410; Sievers Instruments Inc.) without a nose-clip before the single exhalation maneuver. Ambient air NO was recorded before and after each test. FENO levels were measured at the plateau of the end exhaled reading and expressed as parts per billion (ppb). At least three measurements that varied by $<10 \%$ or two measurements that varied by $<5 \%$ were recorded. Mean values of the respective plateaux were evaluated.

\section{Six minutes walking test}

The 6-min walking distance (6 MWD) test was performed, at admission to the study, in 6 COPD with PAH, according to standard method [34].

\section{Statistical analysis}

Data are presented as mean value \pm standard deviation (SD). As the data presented normal distribution (Kolmogorov-Smirnov test), parametric tests were used for statistical analysis. Analysis of variance (ANOVA) was used to perform comparisons between groups. Relationships between patients' characteristics were evaluated using Pearson correlation coefficients. Comparisons of means \pm SD among the groups were made by an unpaired t-test. Significance was established at a p-value $<0.05$. StatView version 5.0 (SAS Institute, Cary, N.C., USA) was used for the statistical analysis. Both, correlations between clinical parameters and exhaled or circulating levels of ET-1 presented as scattered plots, and exhaled levels of ET-1 and NO expressed as bar graphs, were made by using KaleidaGraph program (Version 3.02, Synergy soft-ware, PA, USA).

\section{Results}

Demographic and clinical characteristics of 63 individuals recruited are presented in table 1. Endothelin-1 was detectable in the exhaled breath as well as in the blood of all subjects. The reproducibility of repeated ET-1 measurements was quite good, and was assessed by the Bland and Altman method [32] in six patients (mean difference 0.62 $\pm 1.214)$. NO was detectable in the exhaled of all individuals. All COPD patients were investigated with Echo-Doppler and then assigned to one of two groups according to the level of PaPs, using a cut-off of $35 \mathrm{mmHg}$. Those with a PaPs $\geq 35 \mathrm{mmHg}$ (Group 1: $\mathrm{N}=12 ; \mathrm{FEV}_{1} \% 39.35 \pm$ 11.45; PaPs $51.08 \pm 12.21 \mathrm{mmHg}$ ), and those with a PaPs $<35 \mathrm{mmHg}$ (Group 2: $\mathrm{N}=36 ; \mathrm{FEV}_{1} \% 48.13 \pm 18.04$; PaPs $26.05 \pm 3.39 \mathrm{mmHg})$. 
Table I: Demographic and clinical characteristics of 63 individuals recruited classified in 3 groups.

\begin{tabular}{|c|c|c|c|}
\hline & Group ofCOPD+PAH $(n=12)$ & Group of COPD $(n=36)$ & Group of $\mathrm{HS}(n=15)$ \\
\hline Sex, M/F & $11 / 1$ & $32 / 4$ & $9 / 6$ \\
\hline Age, Years & $70.8(6.7)$ & $67.6(9.2)$ & $58(9.2)$ \\
\hline Smoking, pack-years & $27(7)$ & $25(6)$ & 0 \\
\hline $\mathrm{FEV}, \%$ & 39.35 (II.45) & $48.13(18.04)$ & 98.05 (II.65) \\
\hline FVC\% & $64.89(14.90)$ & $69.39(19.1)$ & $95.07(13.34)$ \\
\hline $\mathrm{FEV}_{1} / \mathrm{FVC} \%$ & $46.95(6.81)$ & $54.27(12.46)$ & $101.37(8.5)$ \\
\hline $\mathrm{RV} \%$ & $151(38)$ & $143(32)$ & $108(11)$ \\
\hline $\mathrm{PaO}_{2}(\mathrm{mmHg})$ & $60.83(4.76)$ & $64.58(6.16)$ & $97.2(0.7)$ \\
\hline $\mathrm{PaCO}_{2}(\mathrm{mmHg})$ & $39.4(4.27)$ & $41.78(5.01)$ & $38.4(1.5)$ \\
\hline $\mathrm{PaPs}(\mathrm{mmHg})$ & $51.08(12.2)^{*}$ & $26.05(3.39)$ & NA \\
\hline ET-I EBC $(\mathrm{pg} / \mathrm{ml})$ & $22.36(4)$ & $7.25(0.23)$ & $5.24(0.47)$ \\
\hline ET-I art (pg/ml) & $12.4 \mid(2.13)$ & $7.22(0.21)$ & $0.84(0.37)$ \\
\hline ET-I ven $(\mathrm{pg} / \mathrm{ml})$ & $14.53(2.76)$ & $7.29(0.16)$ & I $(0.42)$ \\
\hline FENO (ppb) & $22.92(11.38)$ & $35.07(17.53)$ & $20.56(3.67)$ \\
\hline 6MWD & $383(34)^{\S}$ & NA & NA \\
\hline
\end{tabular}

Pulmonary function, arterial blood gases, pulmonary-artery systolic pressure, exhaled breath condensate counts and circulating levels are expressed in table I. Statistical significant difference was found between groups I and 2 in pulmonary-artery systolic pressure, $\operatorname{PaPs}(\mathrm{P}<0.000 \mathrm{I})$.

Definition of abbreviations

EBC: Exhaled Breath Condensate, ET-I: Endothelin-I, FENO: Exhaled Nitric Oxide, FEV : Forced Expiratory Volume in the first second, FVC: Forced Vital Capacity, HS: Healthy Subjects, NO: Nitric Oxide, PAH: Pulmonary Artery Hypertension, RV: Residual Volume, PaPs: Pulmonaryartery systolic pressure, 6MWD: 6-minutes walking distance

Data are presented as mean $( \pm S D)$

$\mathrm{NA}=$ not applicable

$\S \mathrm{n}=6$ patients

$*$ Significant difference compared to COPD group: $p<0.00$ I

\section{Group of COPD with PAH}

Significantly increased levels of ET-1 in EBC were found in all 12 patients with PAH associated with COPD $\left(\mathrm{FEV}_{1} \%\right.$ $39.35 \pm 11.45, \mathrm{FEV}_{1} / \mathrm{FVC} \% 46.95 \pm 6.81, \mathrm{PaPs} \geq 35$ $\mathrm{mmHg}$ ) (group 1) compared to both COPD only (group 2) $(22.36 \pm 4$ vs $7.25 \pm 0.23 \mathrm{pg} / \mathrm{ml} ; \mathrm{p}<0.0001)$ and to the control subjects (group 3$)(5.24 \pm 0.47 \mathrm{pg} / \mathrm{ml} ; \mathrm{p}<0.0001)$ (Figure 1). Higher circulating levels of ET-1 both in the arterial and in the venous sample were found in group 1 compared to all other groups. Arterial levels were increased as compared to group $2(12.41 \pm 2.13$ vs $7.22 \pm$ $0.21 \mathrm{pg} / \mathrm{ml} ; \mathrm{p}<0.0001)$ and to the controls $(0.84 \pm 0.37$ $\mathrm{pg} / \mathrm{ml} ; \mathrm{p}<0.0001$ ) (Figure 2). We also observed increased levels of ET-1 in the venous blood statistically significant compared to both group $2(14.53 \pm 2.76$ vs $7.29 \pm 0.16$ $\mathrm{pg} / \mathrm{ml} ; \mathrm{p}<0.0001)$, and to the control group $(1 \pm 0.42 \mathrm{pg} /$ $\mathrm{ml} ; \mathrm{p}<0.0001$ ) (Figure 3 ). Thus, significantly over-expression of ET-1 was found in COPD with PAH compared to COPD only. With regards to disease severity, in COPD with PAH, Pearson correlation analysis showed a good relationship between ET-1 in EBC and pulmonary-artery systolic pressure $(\mathrm{PaPs})(\mathrm{r}=0.621 ; \mathrm{p}=0.031)$ (Figure 4); A positive correlation was also observed between arterial blood levels of ET- 1 and PaPs $(\mathrm{r}=0.648 ; \mathrm{p}=0.022)$ (Figure 5), while the arterial blood levels of ET-1 inversely correlated to the $\mathrm{FEV}_{1} \%$ of the group $1(\mathrm{r}=-0.59, \mathrm{p}=0.043)$ (Figure 6). Furthermore, PaPs inversely correlated with $\mathrm{PaO}_{2}$ in this group of patients $(\mathrm{r}=-0.618 ; \mathrm{p}=0.032)$ (Figure 7). ET-1 levels in venous blood, although higher than arterial levels $(14.53 \pm 2.76$ vs. $12.41 \pm 2.13)$, did not correlate with any parameter considered in this group of patients.

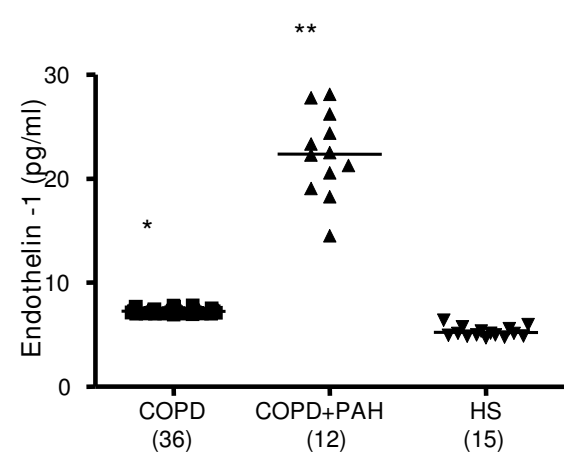

$* * \mathrm{p}<0.0001$ vs all

$* \mathrm{p}<0.0001$ vs HS

\section{Figure I}

Endothelin-I (expressed as $\mathrm{pg} / \mathrm{ml}$ ) concentration in EBC of the 3 groups: COPD (36), COPD + PAH (12), and healthy subjects (HS) (I5). Significance was established at a $p$ value $<0.05$. The horizontal lines represent median value. $E T-I$ in $E B C$ was increased in all COPD patients compared to control group ( $p<0.0001)$. In COPD+PAH group, ET-I levels were significantly increased compared to both the COPD only and the control group ( $\mathrm{P}$ $<0.000$ I). 


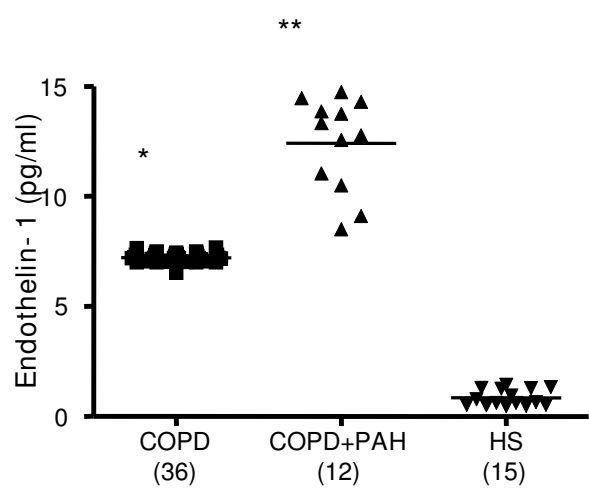

$* * \mathrm{p}<0.0001$ vs all

$* \mathrm{p}<0.0001$ vs HS

Figure 2

Endothelin-I (expressed as pg/ml) levels in the arterial blood of the 3 groups: COPD (36), COPD + PAH (I2), and healthy subjects (HS) (I5). Significance was established at a $p$ value $<0.05$. The horizontal lines represent median value. ET-I in arterial sample was increased in all COPD patients compared to control group ( $p<0.000 \mathrm{I})$. In COPD+PAH group, ET-I levels were significantly increased compared to both the COPD only and healthy controls $(\mathrm{P}<$ $0.0001)$.

In COPD patients with PAH, we found significantly reduced levels of FENO compared to COPD only (22.92 \pm 11.38 vs.35.07 $\pm 17.53 \mathrm{ppb} ; \mathrm{p}=0.03$ ) (Figure 8). These levels were not different compared to the FENO levels of the control group $(20.56 \pm 3.67 \mathrm{ppb} ; \mathrm{p}=0.45)$ (Figure 8). An imbalanced output in the breath between ET-1 and $\mathrm{NO}$ was seen in this group of patients. As shown in figure 9, ET-1 levels were significantly increased in COPD with PAH compared to COPD only ( $\mathrm{p}<0.0001)$, while FENO levels in group 1 were significantly lower than group 2 levels $(p=0.03)$. FENO levels did not significantly correlate with any clinical feature.

\section{Group of COPD only}

In $36 \mathrm{COPD}$ patients $\left(\mathrm{FEV}_{1} \% 48.13 \pm 18.04, \mathrm{FEV}_{1} / \mathrm{FVC} \%\right.$ $54.27 \pm 12.46$, PaPs $<35 \mathrm{mmHg}$ ) ET-1 levels in EBC were significantly higher than control group levels $(5.24 \pm 0.47$ $\mathrm{pg} / \mathrm{ml} ; \mathrm{p}<0.0001$ ) (Figure 1 ). Increased concentrations of ET-1 in the arterial, as well as in the venous blood, compared to the control group, were found in group $2(7.22 \pm$ 0.21 vs. $0.84 \pm 0.37 \mathrm{pg} / \mathrm{ml} ; \mathrm{p}<0.0001 ; 7.29 \pm 0.16 \mathrm{pg} / \mathrm{ml}$ vs. $1.00 \pm 0.42 \mathrm{pg} / \mathrm{ml} ; \mathrm{p}<0.0001$ ) (Figures 2, 3). FENO levels in COPD were statistically significant higher than control group levels $(35.07 \pm 17.53$ vs. $20.56 \pm 3.67$ ppb; $\mathrm{p}=0.003$ ), (Figure 8). Two COPD patients showed higher NO levels, similar to those detected in asthma and not in COPD, but we excluded that those levels were related to an atopic status, on the basis of the IgE total concentra-

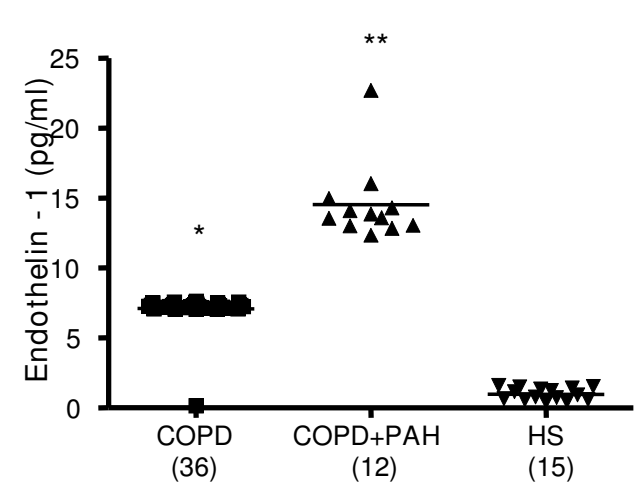

** $\mathrm{p}<0.0001$ vs all

* $\mathrm{p}<0.0001$ vs HS

Figure 3

Endothelin-I (expressed as $\mathrm{pg} / \mathrm{ml}$ ) concentration in the venous blood of the 3 groups: COPD (36), COPD + PAH (12), and healthy subjects (HS) (15). Significance was established at a $p$ value $<0.05$. The horizontal lines represent median value. ET-I in venous sample was increased in all COPD patients compared to control group $(p<0.000 I)$. In COPD+PAH group, ET-I levels were significantly increased compared to both the COPD only and the controls $(p<0.000 I)$.

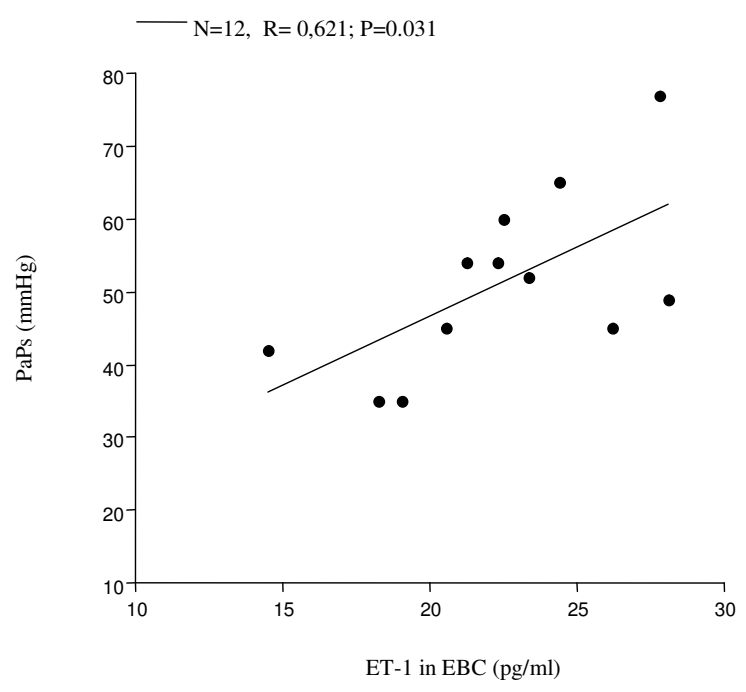

Figure 4

COPD+PAH: linear regression shows good correlation between ET-I levels in the EBC and PaPs (N = I 2; $r=0.62 I ; p=0.03 I$ ). 


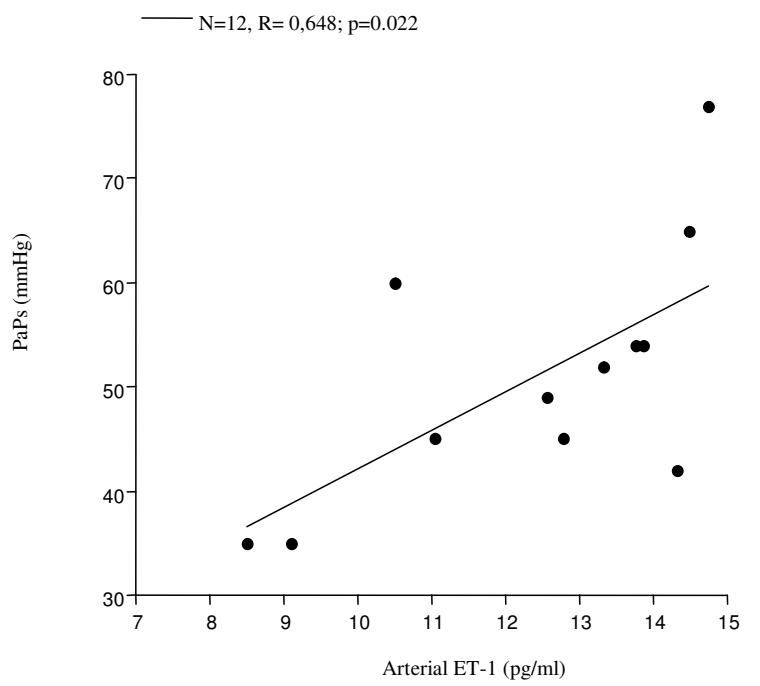

Figure 5

COPD+PAH: positive correlation between arterial blood levels of ET-I and PaPs (N = I2, $r=0.65 ; p=$ 0.022).

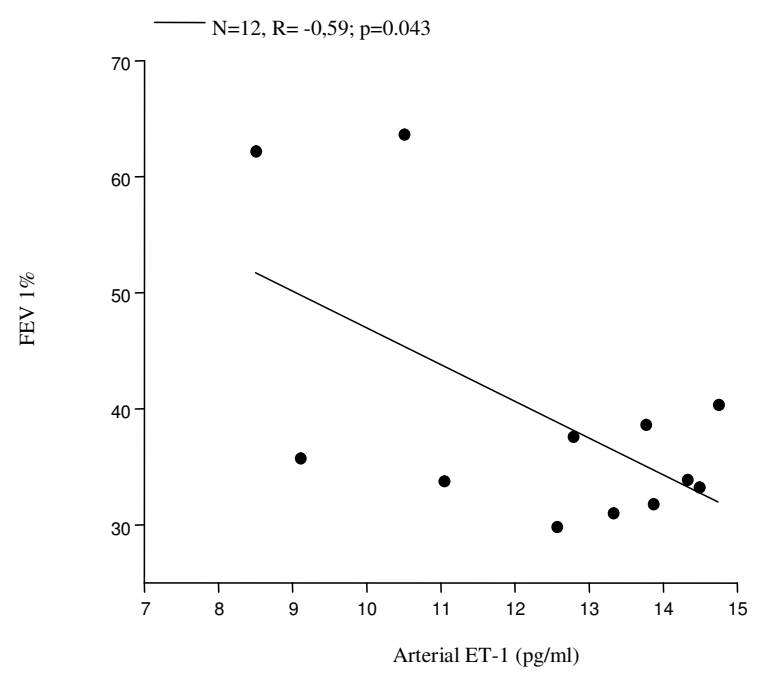

Figure 6

COPD+PAH: negative correlation between $\mathrm{FEV}_{1} \%$ and arterial blood levels of ET-I (N= I2, r = -0.59, $p=$ 0.043).

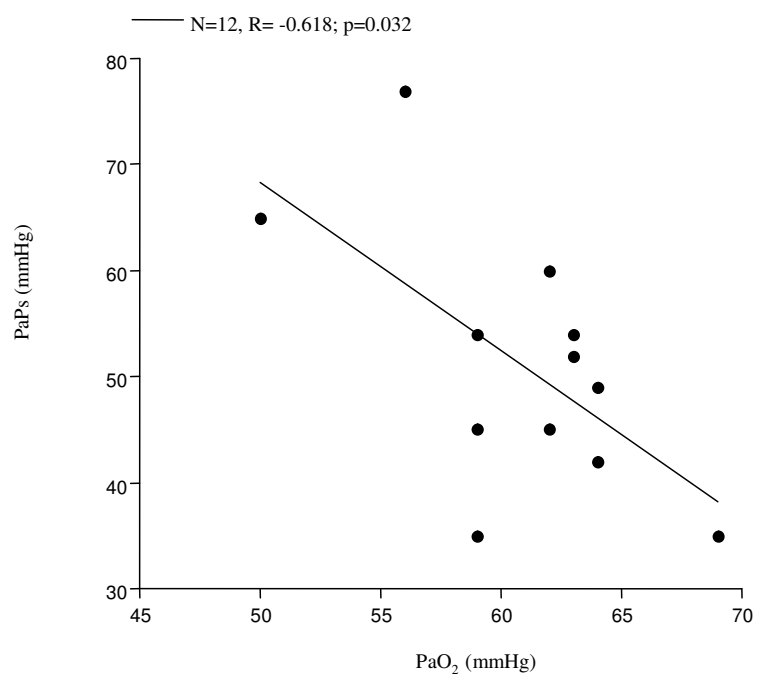

Figure 7

COPD+PAH: negative correlation between PaPs and $\mathrm{PaO}_{2}(\mathrm{~N}=12, \mathrm{r}=-0.618 ; \mathrm{p}=0.032)$.

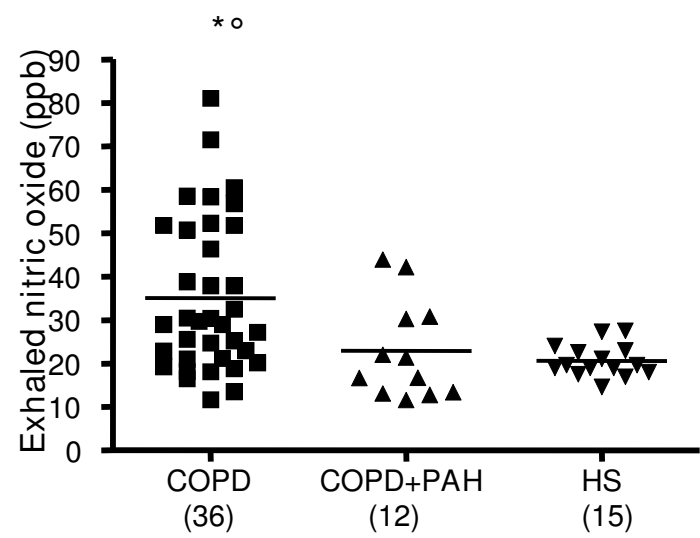

*p $=0.03$ vs COPD $+\mathrm{PAH}$

${ }^{\circ} \mathrm{p}=0.003$ vs $\mathrm{HS}$

\section{Figure 8}

Exhaled nitric oxide concentrations (FENO), expressed as ppm, in 3 groups: COPD (36),

COPD+PAH (12), and healthy subjects (HS) (15). Significance was established at a $p$ value $<0.05$. The horizontal lines represent median value. FENO levels were significantly higher in COPD only, compared to both the COPD with PAH $(p=0.03)$, and the controls $(p=0.003)$. There was no significant relationship between FENO levels in COPD+PAH compared to the control group levels $(p=0.45)$. 


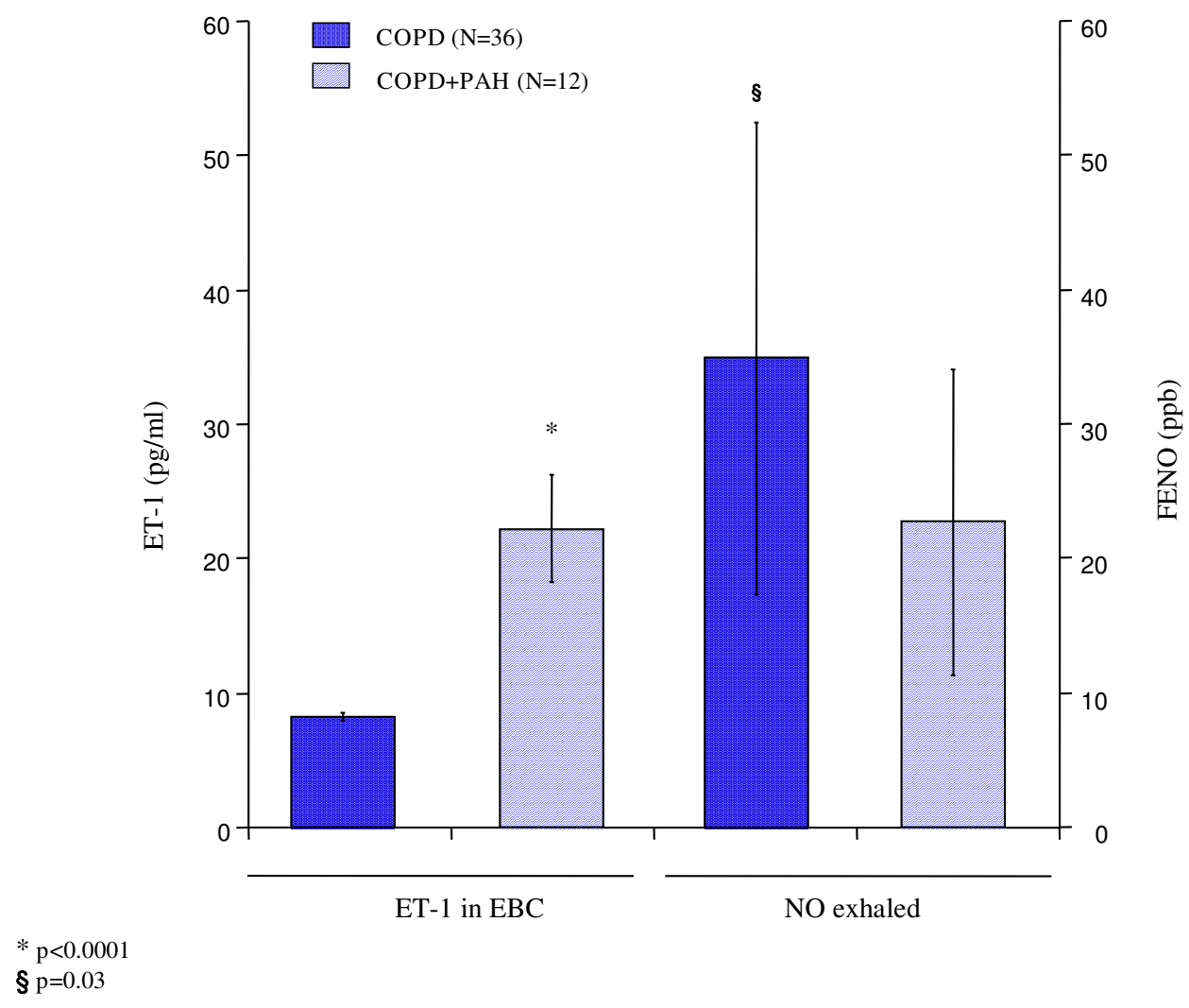

\section{Figure 9}

An imbalance between exhaled condensate ET-I concentrations and exhaled nitric oxide concentrations (FENO) in COPD (36), and in COPD+PAH (12). In COPD+PAH group, ET-I levels were significantly increased compared to the COPD only $(P<0.000 I)$. FENO levels were significantly higher in COPD only, compared to both the COPD with PAH ( $p=0.03)$.

tion. ET-1 and NO levels did not significantly correlate to any baseline characteristic in this group of patients.

\section{Discussion}

In the natural history of COPD, right heart failure leading to increased pulmonary artery pressure is a common finding $[35,36]$. PAH, in this scenario, is likely due to a primary hypoxic vasoconstriction associated to the direct toxic effect of tobacco smoke into the intrapulmonary vessels, with abnormal production of substances that control vasoconstriction, vasodilatation, and vascular cell proliferation, ultimately leading to extensive pulmonary artery remodelling [2,37]. Early detection of an imbalanced output between essential mediators, such as endothelin-1 and $\mathrm{NO}$, might be a novel approach to rapidly investigate and eventually treat this critical disease. The present study was designed to investigate endothelin- 1 and NO concentration in the exhaled breath, as well as circulating levels of ET-1 in COPD patients with or without pulmonary hypertension. Our findings show that endothelin-1 levels in EBC are increased in all COPD patients. In addition, we observed ET-1 levels in EBC significantly higher in COPD associated with $\mathrm{PAH}$, compared to COPD only. Several previous studies detected elevated levels of ET- 1 in EBC in interstitial pulmonary disease [38], in non small cell lung cancer patients (NSCLC) [39], and in unstable bronchial asthma [40], similar to those observed in our COPD patients, while in the present, we found significantly higher EBC levels of ET-1 in COPD with PAH. Carpagnano and colleagues hypothesized that ET-1, in pathological conditions (interstitial pulmonary disease and NSCLC), could be in part produced by airway epithelium itself $[38,39]$, while the reason of an exaggerated ET-1 release in EBC in COPD with PAH is still unknown. However, it appears that ET-1, primary produced by the pulmonary endothelium, could be in part generated by the epithelium, and, in addition, could be partially the result of an uptake into the airway epithelium. Furthermore, we 
found elevated circulating levels of ET-1 in arterial and venous samples in COPD, and significantly higher levels in COPD with PAH. Increased circulating ET-1 levels have been recently shown in exacerbation of COPD [41], whereas there are still controversial data about ET-1 levels in the blood of patients with PAH associated with COPD or emphysema [19-21]. While a study disclosed increased levels of ET-1 only in pulmonary arterial sample [19], two reports showed persistent increased circulating ET-1 levels, which correlated to the severity of pulmonary hypertension $[20,21]$. In our group of COPD patients with PAH, ET-1 levels in arterial sample positively correlated with PaPs, however we provide new evidence that also ET1 in EBC is related to PaPs. Interestingly, in the same group, we observed a negative correlation between ET-1 levels in arterial blood and $\mathrm{FEV}_{1} \%$, but not between ET-1 levels in EBC and $\mathrm{FEV}_{1} \%$. This finding sustains the previous hypothesis that pulmonary endothelium represents the mayor source of ET-1, which could be only in part produced by the airway epithelium, where it may contribute to induce partial bronchoconstriction, although the latter observation needs to be validated by further histological evidences. As previously demonstrated [42], an inverse correlation between PaPs and $\mathrm{PaO}_{2}$ was observed in this group, confirming that pulmonary artery pressure and $\mathrm{PaO}_{2}$ are closely negatively related in $\mathrm{PAH}$ induced by COPD. Regarding to exhaled NO, we found reduced levels of FENO in COPD with PAH compared to the group of COPD. Clini and co-workers previously showed reduced levels of FENO in PAH induced by COPD compared to COPD only, which negatively correlated with PaPs [27]. In our experience, FENO levels were also significantly lower in these patients, but we failed to find correlation with Echo-Doppler assessment. In summary, we observed a pathological dysregulation output in the breath between ET-1 and NO in COPD with PAH. Whether the imbalance in the release of these two mediators is an early cause or result of pulmonary hypertension due to COPD is unknown, however the easy and quick detection by a noninvasive and useful assay might encourage further investigations.

This study has different limitations, likely due to methodological assays. First, the control group consisted by healthy non smokers, and not by ex-smokers with no airflow obstruction, that would have been represented a better control group. However our COPD patients were all non smokers from at least 1 year, we consider that smoking habit might not have significantly influenced exhaled breath results. Second, in COPD patients, the pulmonary arterial pressure was evaluated by echocardiography analysis, which does not correspond to the gold standard; however in 4 patients was previously performed a right heart catheterization and the results were comparable with the echo Doppler assessment. Moreover, although no COPD patient was under steroid treatment, we could not exclude that other treatments, such as antihypertensive, nitro-derivate, or other drugs, might have influenced the results. Finally, no significant difference in the treatment between COPD and COPD with pulmonary hypertension was evident.

\section{Conclusion}

In conclusion, we found increased expression of ET-1 in EBC and in the blood, in COPD patients with PAH compared to COPD only. ET-1 levels, both in EBC and in the arterial samples, positively correlated to pulmonary-artery systolic pressure, while arterial concentration of ET-1 negatively correlated with $\mathrm{FEV}_{1} \%$, indicating that enhanced ET-1 levels in biological sample might early occur in PAH secondary to COPD, and actively participate in stimulating vascular and airway remodelling, through an endogenous increased production by the endothelium, and by a partial release and uptake into the airway epithelium. Finally, we showed an imbalance output in the breath between ET- 1 and NO in this group of patients, suggesting that suppression of $\mathrm{NO}$, in pulmonary hypertension, might have been caused in part by ET-1 [43]. Although the novel treatment for pulmonary artery hypertension has been used successfully for IPAH, it remains to be investigated with randomized multicentric studies whether this new therapy could provide beneficial clinical effects in PAH secondary to COPD.

\section{Abbreviations}

ATS: American Thoracic Society; COPD: Chronic Obstructive Pulmonary Disease; $\mathrm{D}_{\mathrm{L}} \mathrm{CO}$ : Carbon monoxide diffusion capacity; EBC: Exhaled Breath Condensate; ERS: European Respiratory Society; ET-1: Endothelin-1; FENO: Exhaled Nitric Oxide; $\mathrm{FEV}_{1}$ : Forced Expiratory Volume in the first second; FVC: Forced Vital Capacity; HS: Healthy Subjects; NO: Nitric Oxide; PAH: Pulmonary Artery Hypertension; IPAH: Idiopathic Pulmonary Artery Hypertension; PaPs: Pulmonary-artery systolic pressure; ppb: parts per billion; RV: Residual Volume; 6MWD: 6-minutes walking distance.

\section{Competing interests}

The authors declare that they have no competing interests.

\section{Authors' contributions}

PC designed the study, carried out the laboratory research and the patients' characterisation for the classification of the different patient groups, and wrote the manuscript. CS designed the study, recruited the patients, coordinated the study, and assisted in performing the statistical analysis. MM performed the statistical analysis, participated in interpretation of results, in writing the manuscript, and critically reviewed the manuscript. TSM assisted in the patients' characterisation, performed laboratory analysis 
and interpretation of results. GDG recruited the patients and helped with study design. FG assisted in the patients' characterisation, in statistical analysis, and interpretation of results. RAC performed the statistical analysis and participated in reviewing the manuscript. SD assisted in the patients' characterisation and in statistical analysis. PP recruited the patients and helped with study design. AS participated in interpretation of results and critically reviewed the manuscript. OR conceived and supervised the study as head of the lung research group, participated in its design and coordination and revised the manuscript. All authors read and approved the final manuscript.

\section{Aknowledgments}

The authors would like to thank Gaia Iacoviello MD, Fabio Cardinale MD, and G. Elisiana Carpagnano MD, for technical support

\section{References}

I. Bishop JM: Cardiovascular complication of chronic bronchitis and emphysema. Med Clin North Am 1973, 57:771-780.

2. Naeije R, Barbera JA: Pulmonary hypertension associated with COPD. Crit Care 200I, 5(6):286-9.

3. Weitzenblum E, Hirth C, Ducolone A, Mirhom R, Rasaholinjanahary $J$, Ehrhart M: Prognostic value of pulmonary artery pressure in chronic obstructive pulmonary disease. Thorax |98|, 36(10):752-8.

4. Fernie JM, McLean A, Lamb D: Significant intimal abnormalities in muscular pulmonary arteries of patients with early obstructive lung disease. J Clin Pathol I988, 4 I (7):730-3.

5. Beghe B, Bazzan E, Baraldo S, Calabrese F, Rea F, Loy M, Maestrelli P, Zuin R, Fabbri LM, Saetta M: Transforming growth factor-beta type II receptor in pulmonary arteries of patients with very severe COPD. Eur Respir J 2006, 28(3):556-62.

6. Santos S, Peinado VI, Ramirez J, Melgosa T, Roca J, Rodriguez-Roisin $R$, Barbera JA: Characterization of pulmonary vascular remodelling in smokers and patients with mild COPD. Eur Respir 2002, 19(4):632-8.

7. Wright JL, Tai H, Churg A: Cigarette smoke induces persisting increases of vasoactive mediators in pulmonary arteries. Am J Respir Cell Mol Biol 2004, 3 I:50 I-9.

8. Christman BW, McPherson CD, Newman JH, King GA, Bernard GR, Groves BM, Loyd JE: An imbalance between the excretion of thromboxane and prostacyclin metabolites in pulmonary hypertension. N Engl J Med 327(2):70-5.

9. Yanagisawa M, Kurihara H, Kimura S, Tomobe $Y$, Kobayashi M, Mitsui Y, Yazaki Y, Goto K, Masaki T: A novel potent vasoconstrictor peptide produced by vascularendothelial cells. Nature 332(6I63):4III-5.

10. Springall DR, Howarth PH, Counihan H, Djukanovic R, Holgate ST, Polak JM: Endothelinimmunoreactivity of airway epithelium in asthmatic patients. Lancet 337(8743):697-70I.

II. Wort SJ, Woods M, Warner TD, Evans TW, Mitchell JA: Endog. enously released endothelin-I from human pulmonary artery smooth muscle promotes cellular proliferation: relevance to pathogenesis of pulmonary hypertension and vascular remodeling. Am J Respir Cell Mol Biol 200I, 25(I): 104-I0.

12. Glassberg MK, Ergul A, Wanner A, Puett D: Endothelin-I promotes mitogenesis in airway smooth muscle cells. Am J Respir Cell Mol Biol I994, 10(3):316-2I.

13. Davie N, Haleen SJ, Upton PD, Polak JM, Yacoub MH, Morrell NW, Wharton J: ET(A) and ET(B) receptors modulate the proliferation of human pulmonary artery smooth muscle cells. $\mathrm{Am} J$ Respir Crit Care Med 165(3):398-405.

14. Carratu P, Scuri M, Styblo JL, Wanner A, Glassberg MK: ET-I induces mitogenesis in ovine airway smooth muscle cells via ETA and ETB receptors. Am J Physiol 1997, 272(5 Pt I):LI 02 I-4.

15. Giaid A, Yanagisawa M, Langleben D, Michel RP, Levy R, Shennib H Kimura S, Masaki T, Duguid WP, Stewart DJ: Expression of endothelin- $I$ in the lungs of patients with pulmonary hypertension. N Engl J Med 328(24): I732-9.

16. Ferri C, Bellini C, De Angelis C, De Siati L, Perrone A, Properzi G, Santucci A: Circulating endothelin-I concentrations in patients with chronic hypoxia. J Clin Pathol 1995, 48(6):5 I 9-24.

17. Sofia M, Mormile M, Faraone S, Carratu P, Alifano M, Di Benedetto G, Carratu L: Increased 24-hour endothelin-I urinary excretion in patients with chronic obstructive pulmonary disease. Respiration 1994, 6I(5):263-8.

18. Chalmers GW, Macleod KJ, Sriram S, Thomson LJ, McSharry C, Stack $\mathrm{BH}$, Thomson NC: Sputum endothelin-I is increased in cystic fibrosis and chronic obstructive pulmonary disease. Eur Respir J 1999, I 3(6): 1288-92

19. Celik G, Karabiyikoglu G: Local and peripheral plasma endothelin-I in pulmonary hypertension secondary to chronic obstructive pulmonary disease. Respiration 1998, 65(4):289-94.

20. Cody RJ, Haas G], Binkley PF, Capers Q, Kelley R: Plasma endothelin correlates with the extend of pulmonary hypertension in patients with chronic congestive heart failure. Circulation 1992, 85:504-509.

21. Yamakami T, Taguchi O, Gabazza EC, Yoshida M, Kobayashi T, Kobayashi $H$, Yasui $H$, Ibata $H$, Adachi $Y$ : Arterial endothelin- I level in pulmonary emphysema and interstitial lung disease. Relation with pulmonary hypertension during exercise. Eur Respir J 1997, I0(9):2055-60.

22. Furchgott RF, Zawadzki JV: The obligatory role of endothelia cells in the relaxation of arterial smooth muscle by acetylcholine. Nature 288(5789):373-6.

23. Dinh-Xuan AT: Endothelial modulation of pulmonary vascular tone. Eur Respir J 1992, 5(6):757-62. Review.

24. Ozaki M, Kawashima S, Yamashita T, Ohashi Y, Rikitake Y, Inoue N, Hirata KI, Hayashi Y, Itoh H, Yokoyama M: Reduced hypoxic pulmonary vascular remodeling by nitric oxide from the endothelium. Hypertension 200I, 37(2):322-7.

25. Dinh-Xuan AT, Higenbottam TW, Clelland CA, Pepke-Zaba J, Cremona G, Butt AY, Large SR, Wells FC, Wallwork J: Impairment of endothelium-dependent pulmonary-artery relaxation in chronic obstructive lung disease. N Engl] Med 324(22): I539-47.

26. Corradi M, Majori M, Cacciani GC, Consigli GF, de'Munari E, Pesci A: Increased exhaled nitric oxide in patients with stable chronic obstructive pulmonary disease. Thorax 1999, 54(7):572-5.

27. Clini E, Cremona G, Campana M, Scotti C, Pagani M, Bianchi L, Giordano A, Ambrosino N: Production of endogenous nitric oxide in chronic obstructive pulmonary disease and patients with cor pulmonale. Correlates with echo-Doppler assessment. Am J Respir Crit Care Med 2000, 162(2 Pt I):446-50.

28. Barnes PJ, Chowdhury B, Kharitonov SA, Magnussen H, Page CP, Postma D, Saetta M: Pulmonary biomarkers in chronic obstructive pulmonary disease. Am J Respir Crit Care Med I74(I):6-14.

29. Standards for the diagnosis and care of patients with chronic obstructive pulmonary disease. American Thoracic Society. Am J Respir Crit Care Med 1995, I52(5 Pt 2):S77-I2I.

30. American Thoracic Society. Standardization of spirometry, 1994 update. Am J Respir Crit Care Med 1995, I 52: I I07-I I 36.

31. Berger M, Haimowitz A, Van Tosh A, Berdoff RL, Goldberg E: Quantitative assessment of pulmonary hypertension in patients with tricuspid regurgitation using continuous wave Doppler ultrasound. J Am Coll Cardiol 1985, 6(2):359-65.

32. Bland JM, Altman DG: Statistic notes: measurement error. $B M]$ 1996, 3 1 3:744-750.

33. ATS Workshop proceedings: exhaled nitric oxide and nitric oxide oxidative metabolism in exhaled breath condensate. Proc Am Thorac Soc 2006, 3: $131-145$.

34. ATS Committee on Proficiency Standards for Clinical Pulmonary Function Laboratories. ATS statement: guidelines for the six-minute walk test. Am J Respir Crit Care Med I66(I): III-7.

35. Kessler R, Faller M, Weitzenblum E, Chaouat A, Aykut A, Ducolone A, Ehrhart M, Oswald-Mammosser M: "Natural history" of pulmonary hypertension in a series of I 3 I patients with chronic obstructive lung disease. Am J Respir Crit Care Med 200I, 164:219-224.

36. Scharf SM, lqbal M, Keller C, Criner G, Lee S, Fessler HE: National Emphysema Treatment Trial (NETT) Group. Hemodynamic characterization of patients with severe emphysema. Am J Respir Crit Care Med 166(3):3।4-22. 
37. Wright JL, Levy RD, Churg A: Pulmonary hypertension in chronic obstructive pulmonary disease: current theories of pathogenesis and their implications for treatment. Thorax 2005, 60(7):605-9.

38. Carpagnano GE, Kharitonov SA, Wells AU, Pantelidis P, Du Bois RM, Barnes PJ: Increased vitronectin and endothelin-I in the breath condensate of patients with fibrosing lung disease. Respiration 2003, 70(2): 154-60.

39. Carpagnano GE, Foschino-Barbaro MP, Resta O, Gramiccioni E, Carpagnano F: Endothelin-I is increased in the breath condensate of patients with non-small-cell lung cancer. Oncology 2004, 66(3):180-4.

40. Zietkowski Z, Skiepko R, Tomasiak MM, Bodzenta-Lukaszyk A: Endothelin- $I$ in exhaled breath condensate of stable and unstable asthma patients. Respir Med 2008, 102(3):470-4.

4I. Roland M, Bhowmik A, Sapsford RJ, Seemungal TA, Jeffries DJ, Warner TD, Wedzicha JA: Sputum and plasma endothelin- $I$ levels in exacerbations of chronic obstructive pulmonary disease. Thorax 200I, 56(I):30-5.

42. Weitzenblum E, Sautegeau A, Ehrhart M, Mammosser M, Hirth C, Roegel $E$ : Long-term course of pulmonary arterial pressure in chronic obstructive pulmonary disease. Am Rev Respir Dis 1984, I 30(6):993-8.

43. Girgis RE, Champion HC, Diette GB, Johns RA, Permutt S, Sylvester JT: Decreased exhaled nitric oxide in pulmonary arterial hypertension: response to bosentan therapy. Am J Respir Crit Care Med 172(3):352.

\section{Pre-publication history}

The pre-publication history for this paper can be accessed here:

http://www.biomedcentral.com/1471-2466/8/20/prepub

Publish with Biomed Central and every scientist can read your work free of charge

"BioMed Central will be the most significant development for disseminating the results of biomedical research in our lifetime. "

Sir Paul Nurse, Cancer Research UK

Your research papers will be:

- available free of charge to the entire biomedical community

- peer reviewed and published immediately upon acceptance

- cited in PubMed and archived on PubMed Central

- yours - you keep the copyright 